\title{
Revista Annaes de Enfermagem: publicações de enfermeiras sobre pediatria (1932-1941)
}

\author{
Revista Annaes de Enfermagem: nurses' publications about pediatrics (1932-194I)
}

Revista Annaes de Enfermagem: publicaciones de enfermeras sobre pediatria (1932-194I)

\author{
Aline Silva Fontes', Tânia Cristina Franco Santos', Alexandre Barbosa de Oliveira' \\ 'Universidade Federal do Rio de Janeiro. Escola de Enfermagem Anna Nery. Rio de Janeiro, RJ
}

Submissão: 10/12/2007

Aprovação: 23/1 1/2008

\section{RESUMO}

Estudo histórico-social Que tem como objeto a produção intelectual de enfermeiras e estudantes de enfermagem relativas à enfermagem pediátrica na revista Annaes de Enfermagem, no período entre 1932-1941. A fonte primária refere-se aos números da revista Annaes de Enfermagem pertencentes ao recorte temporal do estudo, além de relatórios e correspondências. As fontes secundárias estão constituídas de livros, artigos, dissertações e teses relativas à história do Brasil e da enfermagem. A análise dos dados teve o apoio das fontes secundárias e do pensamento do sociólogo francês Pierre Bourdieu. Os resultados evidenciam Que a revista Annaes de Enfermagem publicou e divulgou temas importantes sobre a assistência de enfermagem à criança e contribuiu para a visibilidade da enfermeira brasileira junto à comunidade científica.

Descritores: História da Enfermagem; Enfermagem pediátrica; História.

\section{ABSTRACT}

Historic-social study whose object was the intellectual production of nurses and students about pediatric nursing in the journal Annaes de Enfermagem, in the period 1932-1941. The primary source refers to the issues of the journal Annaes de Enfermagem considering the established time limits for the study, as well as reports and correspondences. The secondary sources are constituted by books, articles, dissertations and thesis on the Brazilian history of nursing. On data analysis it was used the thought of the French sociologist Pierre Bourdieu. The results show that the journal Annaes de Enfermagem published important issues of nursing care to the child and contributed to the visibility of Brazilian nurses among the scientific community.

Descriptors: History of nursing; Pediatric nursing; History.

\section{RESUMEN}

Estudio de naturaleza historico-social Que tiene como objeto la producción intelectual de las enfermeras y estudiantes de enfermería relativos a la enfermería pediátrica en el periodico Annaes de Enfermagem, en el período 1932-1941. Las fuentes primarias se refieren a los números de la Revista Annaes de Enfermagem pertenecientes al recorte temporal del estudio, además de los informes y correspondencia. Las fuentes secundarias están compuestas de libros, artículos, tesis y disertaciones sobre la historia de la enfermería de Brasil. El análisis de datos cuenta con el apoyo de fuentes secundarias y el pensamiento del sociólogo francés Pierre Bourdieu. Los resultados muestran que el periodico Annaes de Enfermería publicó sobre las importantes cuestiones de la asistencia de enfermería para el niño y ha contribuydo con la visibilidad de la enfermera brasileña en la comunidad científica.

Descriptores: Historia de la Enfermería; Enfermería pediátrica; Historia. 


\section{INTRODUÇÃO}

O objeto desse estudo é a produção intelectual de enfermeiras e alunas da Escola de Enfermagem Anna Nery relativas à enfermagem pediátrica na revista Annaes de Enfermagem. O recorte temporal compreende o período de 1932 a 1941. O marco inicial refere-se ao ano da fundação da revista em maio de 1932, com a denominação Annaes de Enfermagem, envolvendo os nomes de Edith de Magalhães Fraenkel, então presidente da Associação Nacional de Enfermeiras Diplomadas Brasileiras (ANEDB), atual Associação Brasileira de Enfermagem e de Rachel Haddock Lobo, diretora da Escola de Enfermeiras D. Anna Nery, atual Escola de Enfermagem Anna Nery da Universidade Federal do Rio de Janeiro. O marco final, 1941, corresponde ao ano em Que a publicação da revista foi interrompida devido às dificuldades financeiras Que as suas dirigentes vinham enfrentando, agravadas pelos altos custos do papel importado, em conseQüência da segunda guerra mundial.

A idéia de criar a revista Annaes de Enfermagem, primeira revista brasileira de enfermagem, surgiu em Montreal, por ocasião da realização do Congresso do Conselho Internacional de Enfermeiras, em 1929, Quando Edith de Magalhães Fraenkel participou da reunião de editoras de revistas das organizações membros da entidade. Também participaram desse evento as enfermeiras brasileiras Rachel Haddock Lobo, Marina Bandeira de Oliveira, Maria de Oliveira Regis e Alayde Duffles Teixeira Lott ${ }^{(1)}$.

Edith de Magalhães Frankel e Rachel Haddock Lobo trabalharam de forma intensa no projeto de criação da revista desde o início de 1930. Em junho de 1931, Rachel Haddock Lobo assumiu a direção da Escola de Enfermagem Anna Nery, em substituição da enfermeira americana, Berta Pullen. Nesse mesmo ano, Edith de Magalhães Frankel substituiu a enfermeira também americana, Ethel Parsons, na Superintendência do Serviço de Enfermeiras do Departamento Nacional de Saúde Pública, Que durante dez anos (1921-1931), chefiou esse serviço. A ocupação de importantes cargos por enfermeiras brasileiras contribuiu para Que a Escola de Enfermagem Anna Nery representasse o centro das atividades inerentes à criação da revista ${ }^{(2)}$.

A revista foi imprensa nas oficinas gráficas do Jornal do Brasil( ${ }^{(1)}$ e lançada no Pavilhão de Aulas da Escola de Enfermagem Anna Nery, em 20 de maio de 1932, data alusiva ao falecimento de Anna Nery. Na oportunidade, Rachel Haddock Lobo, na condição de diretora da escola e redatora-chefe da revista informou Que "o primeiro número da revista estava repleto de homenagens e que os números seguintes tratariam de problemas didáticos”(3).

Dessa forma, já no lançamento da revista, o pronunciamento da redatora-chefe indica a importância atribuída à mesma como um espaço para tratar de temas relativos à prática da enfermeira. Essa assertiva é corroborada por Santos ${ }^{(4)}$ ao afirmar Que a Revista Annaes de Enfermagem representa o primeiro espaço, no Brasil, em Que as enfermeiras tornaram visível a divulgação de seus enunciados com vistas à formação de uma comunidade científica de enfermagem e estruturação do seu campo científico.

O presente estudo parte da premissa de Que a revista Annaes de Enfermagem representou um espaço necessário à publicação dos textos dignos de serem publicados pela nascente comunidade científica de enfermagem, com vistas a legitimar a autoridade científica acerca de sua prática. Interessa nesse estudo, em particular, o Questionamento sobre a forma de expressão da enfermeira e da aluna da Escola de Enfermagem Anna Nery acerca da enfermagem pediátrica, com vistas à compreensão da estruturação desse campo, uma vez Que os periódicos materializam os princípios de visão de mundo social, determinando Que se veja esse mesmo mundo segundo essas divisões.

Para elucidar a problemática em Questão, formulei os seguintes objetivos: caracterizar o ensino de enfermagem pediátrica na Escola de Enfermagem Anna Nery; enumerar as publicações sobre enfermagem pediátrica na Revista Annaes de Enfermagem elaboradas por enfermeiras e alunas da Escola de Enfermagem Anna Nery e analisar a produção intelectual sobre enfermagem de pediátrica á luz dessas publicações.

\section{METODOLOGIA}

Trata-se de um estudo histórico-social cujas fontes primárias, localizadas no Centro de Documentação da Escola de Enfermagem Anna Nery, referem-se aos números da revista Annaes de Enfermagem relativos ao recorte temporal do estudo, relatórios anuais das diretoras, dossiê das alunas, além de correspondências expedidas e recebidas. As fontes secundárias inerentes à temática do estudo foram localizadas na Biblioteca Setorial da Escola de Enfermagem Anna Nery e estão constituídas de livros, artigos, dissertações e teses.

Para análise do material foram realizados os seguintes procedimentos: primeiramente realizou-se a seleção e leitura de todos os textos publicados por enfermeiras e alunas da Escola de Enfermagem Anna Nery, no período de 1932 a 1941, bem como a seleção e leitura dos documentos escritos alusivos à temática. Em seguida, para melhor organização dos dados contidos nos exemplares da revista, foi elaborado um Quadro, o Qual contemplou elementos como: ano de publicação, título, autoria do artigo e síntese do conteúdo do mesmo. A leitura desse material permitiu ainda, a seleção de duas fotografias publicadas em conjunto com o texto publicado, as Quais mereceram reflexões em função do registro do cuidado de enfermeiras e alunas, expressado na composição do texto fotográfico.

A análise dos dados foi feita com o apoio das fontes secundárias e em consonância com o pensamento do sociólogo francês Pierre Bourdieu $^{(5)}$ no Que se refere ao conceito de campo e capital científico, sendo o campo científico por ele considerado como um campo de forças e um campo de lutas para conservar ou transformar esse campo de forças em Que os agentes investem o seu capital científico, sendo este conceituado como "uma espécie particular do capital simbólico Que consiste no reconhecimento (ou no crédito) atribuído pelo conjunto de pares - concorrentes no interior do campo científico"(5).

Nesse sentido, a posição ocupada pelos agentes (enfermeiras) no interior do campo científico orienta e determina suas tomadas de posição Que, em termos práticos comanda os pontos de vista, os lugares de publicação, os temas escolhidos e os objetos interessantes de serem estudados.

O presente estudo se justifica por sua contribuição à história da enfermagem brasileira, mediante uma breve reconstrução de publicações sobre enfermagem pediátrica na Revista Annaes de Enfermagem.

Por fim, vale ressaltar Que o estudo deriva do Projeto de Pesquisa 
intitulado Rituais e Emblemas na Formação da Identidade da Enfermeira Brasileira, coordenado pela Professora Tânia Cristina Franco Santos, apoiado pela FAPERJ, e aprovado pelo Comitê de Ética e Pesquisa da Escola de Enfermagem Anna Nery / Hospital São Francisco de Assis.

\section{RESULTADOS E DISCUSSÃO}

\section{A Enfermagem Pediátrica no Espaço de Escola de Enfermagem Anna Nery}

A Escola de Enfermagem Anna Nery, criada em 1922, no bojo da Reforma Sanitária liderada pelo sanitarista Carlos Chagas, então diretor do Departamento Nacional de Saúde Pública, demarca a implantação da Enfermagem Moderna no Brasil. Com a criação da Escola de Enfermagem Anna Nery, as enfermeiras norte-americanas, patrocinadas pela Fundação Rockfeller, transplantaram para o Brasil um novo modelo de ensino de enfermagem, Que agregava as características do tradicional modelo nightingale, outras, adaptadas aos Estados Unidos, desde os tempos da guerra civil.

O curso, em regime de internato, era dividido em Quatro séries e tinha a duração de dois anos e Quatro meses, completando assim uma carga horária de 800 horas na teoria e 400 horas na prática.

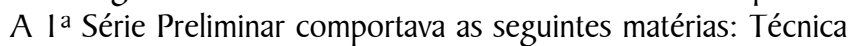
de Enfermagem I e II; Anatomia; Fisiologia; Química; Psicologia, Ética, Higiene, História da Enfermagem e Microbiologia. Na $2^{\mathrm{a}}$ Série, denominada "Júnior", a aluna cursava Patologia Interna; Patologia Externa e Matéria Médica.

A $3^{\text {a }}$ série denominada "Intermediária" diferenciava das anteriores, pois a partir desta a aluna ingressava na parte prática, tendo as matérias divididas em teoria e prática, como: Doenças Contagiosas; Técnica de Sala de Operações; Pediatria; Enfermagem Pediátrica, Dietética Infantil e Ortopedia. $\mathrm{Na} 4^{\text {a }}$ Série as alunas eram chamadas de "Sênior" e cursavam: Doenças Venéreas, Oftalmologia, Higiene; Saúde Pública, Técnica Cirúrgica e O.R.L, ou seja, Otorrinolaringologia.

A parte prática era realizada no Hospital Geral da Assistência (atual Hospital Escola São Francisco de Assis), onde as professoras atuavam também como enfermeiras, prestando assistência e supervisão das alunas nos diversos setores do hospital, de modo a integrar a teoria com a prática. Apesar das dificuldades enfrentadas pelo hospital principalmente durante os anos 30, este continuou sendo campo de estágio das alunas, dando ênfase à assistência infantil.

A Figura I corresponde a uma das aulas sobre Dietética Infantil, onde Rachel Raddock Lobo (figura feminina Que está de véu no centro da imagem) ensina a técnica de pesagem de uma criança à sua aluna, evidenciando a preocupação desta, enQuanto docente e diretora da escola, no ensino correto das técnicas de enfermagem às discentes. À sua esquerda, vê-se a professora e enfermeira Maria de Castro Pamphiro (figura feminina Que utiliza touca com frisos), diante de uma senhora com uma criança no colo, demonstrando a preparação de ensinar a preparação das dietas. O olhar atento da professora indica a atenção ao cuidado bem como a divulgação do ensino das técnicas de enfermagem.

O cenário é o Gabinete de Dietética Infantil, localizado no Hospital São Francisco de Assis, e o corte temporal remete ao ano de 1933.

Em 06 de janeiro de 1934, o Gabinete de Dietética Infantil recebeu a denominação de "Gabinete Rachel Haddock Lobo", em homenagem à ex-diretora da Escola de Enfermagem Anna Nery Que havia falecido em setembro de 1933. Essa homenagem expressa o reconhecimento do corpo docente e discente da escola em relação à preocupação de Rachel para com a clientela infantil. $\mathrm{O}$ gabinete tinha como princípios: assistência médica e educação da mãe no regime de higiene e dietética.

O governo de Getúlio Vargas deu ênfase à clientela infantil, inaugurando dois grandes hospitais pediátricos: Hospital Jesus, em 1935 e Instituto de Puericultura, em 1937. Concomitante ao surgimento de novos hospitais, estes passaram a integrar os campos de estágios das alunas da EEAN, sendo assim a prática em enfermagem pediátrica era realizada de forma onde a aluna pudesse correlacionar as aulas teóricas com a prática realizada por elas nos ambulatórios, enfermarias, clínicas cirúrgicas, berçários e consultórios de puericultura. Com a estruturação do Estado Novo, configura-se um novo modelo de serviço, Qual seja: Puericultura do Distrito Federal, de Cooperação com os Estados e de Estudos e Inquéritos.

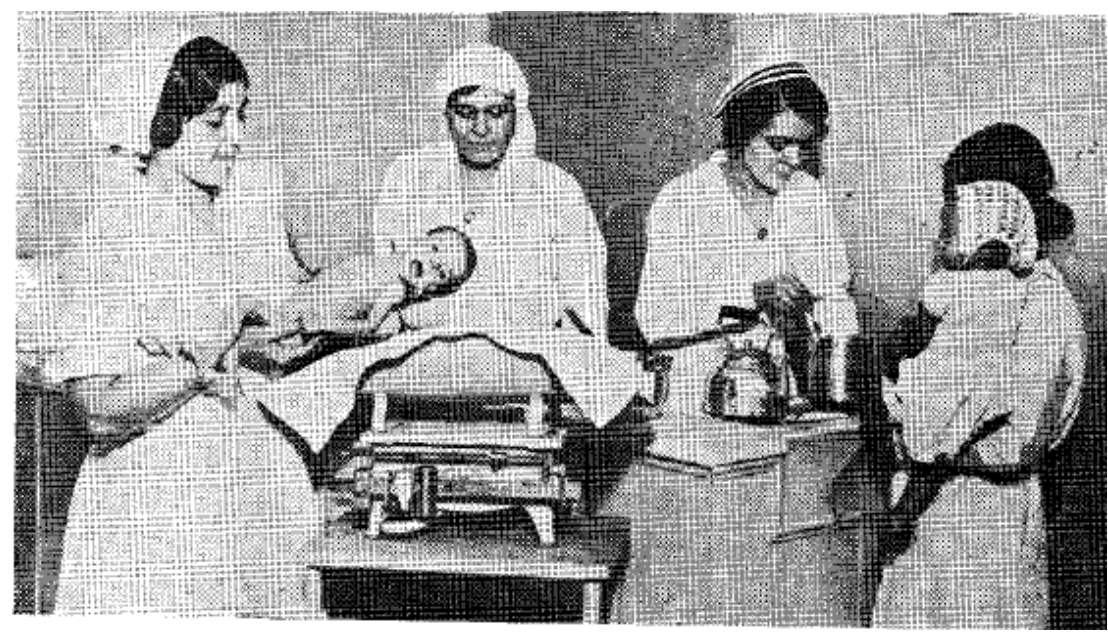

Figura 1. Aula de Dietética no Gabinete de Rachel Haddock Lobo. 
A Revista Annaes de Enfermagem como Veículo Consagrador do Discurso das Enfermeiras sobre Enfermagem Pediátrica

Os artigos sobre pediatria estiveram presentes desde o primeiro número da revista, evidenciando Que a atenção à criança já se configurava como objeto de preocupação das enfermeiras, das alunas de enfermagem e dos médicos, desde a década de 1930. Tais artigos versavam sobre as patologias mais incidentes na clientela infantil; técnicas de enfermagem; cuidados ao recém-nascido; estudos de casos clínicos e organização de serviços de pediatria.

No âmbito da saúde era crescente a atenção direcionada à clientela infantil, devido ao novo pensamento de Que a criança deixara de ser um adulto em miniatura, onde participava de festas noturnas, sem horário para dormir, dormindo no mesmo Quarto Que os adultos, permanecendo a maior parte do tempo na rua, os horários de alimentação não respeitados, entre outros ${ }^{(6)}$.

Na Figura 2 visualiza-se uma enfermeira (figura feminina Que está de touca com frisos) coletando amostras de sangue no calcanhar de um bebê para realizar a triagem neonatal. A enfermeira se apresenta uniformizada e com máscara, demonstrando uma preocupação com a preservação da saúde da criança. Suas mãos parecem tocar de forma cuidadosa à criança.

A fotografia apresenta a seguinte legenda:

"Desde o instante em que o homem surge no mundo até o momento em Que dele se vai é a enfermeira chamada a desempenhar a sua função sublime de assistência, suavizando ou suprimindo a dor, ensinando os preceitos da saúde, restituindo aos Que sofrem a alegria de viver. Na paz, a sua ação bem -faseja exerce-se junto aos berços ou á beira dos leitos de agonia, dos lares pobres, nas fábricas, onde Quer Que se imponha a sua intervenção ou a sua colaboração. Na guerra, afrontando perigos de morte é a enfermeira o anjo tutelar dos soldados tombados no campo de batalha. Divina

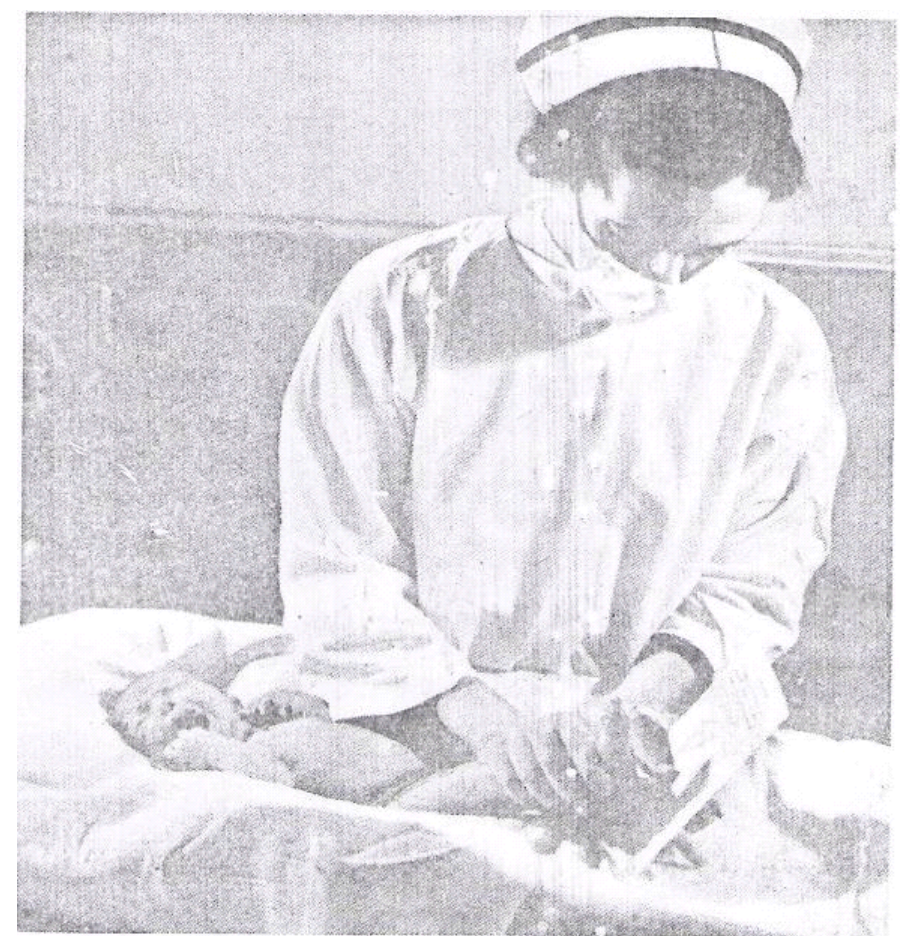

missão a da enfermeira, em todos os lugares e em todos os tempos".

A análise do texto fotográfico evidencia Que o trabalho da enfermeira se configurava como um trabalho feminino, educativo, caritativo e cuidadoso que se fazia presente em todas as etapas de vida do ser humano. Portanto, as características do trabalho da enfermeira enunciadas na legenda Que acompanha a foto são exemplares, no sentido de evocar os atributos intrínsecos à natureza feminina, pois as mulheres foram educadas durante séculos no sentido de dar expressão à sua afetividade ${ }^{(7)}$.

No Que tange as publicações, o Quadro I demonstra Que foram publicados 15 artigos sobre enfermagem pediátrica na Revista Annaes de Enfermagem, sendo 13 artigos de autoria de enfermeiras e 2 de alunas; Predominam os artigos relativos à prática vivenciada por elas nos cenários hospitalares, os Quais retratam a atuação da enfermeira no atendimento à criança, de modo a dar visibilidade à enfermeira.

Os temas abordados pelas enfermeiras e alunas refletem suas preocupações no Que se refere ao cuidado à criança, no sentido de construir e divulgar um corpo sólido de conhecimentos relativos à execução do cuidado de enfermagem, de modo a legitimar o discurso das enfermeiras da Escola de Enfermagem Anna Nery acerca da criança.

Os textos foram recorrentes em relação à preocupação com a higiene infantil, considerada como princípio norteador da saúde. Tanto assim, Que a preocupação com a higiene já se expressava no atendimento à gestante e futura nutriz.

\section{CONSIDERAÇÔES FINAIS}

A revista Annaes de Enfermagem além de oportunizar a discussão de temas relevantes sobre a prática profissional proporcionou visibilidade à enfermeira brasileira junto à comunidade científica, mediante a veiculação de seus textos. Refletindo sobre o tema, não se pode esquecer, na esteira do pensamento do sociólogo francês Pierre Bourdieu Que, o poder Quase mágico das palavras resulta do efeito Que têm a objetivação e a oficialização do fato Que a nomeação pública realiza a vista de todos, tornando o grupo manifesto, para outros grupos e para ele próprio, atestando assim a sua existência como grupo conhecido e reconhecido, Que aspira à institucionalização.

Assim, os textos produzidos por enfermeiras e alunas da Escola de Enfermagem Anna Nery na revista Annaes de Enfermagem tiveram o efeito simbólico de conferir poder e prestígio à enfermeira brasileira, mediante o conhecimento e reconhecimento de sua competência e autoridade científica nas Questões relativas à enfermagem pediátrica, através das publicações nas revistas de enfermagem.

Figura 2. Enfermeira realizando triagem neonatal. 


\begin{tabular}{|c|c|c|c|}
\hline Ano & Título do Artigo & Autora & Síntese \\
\hline 1932 & Enfermagem Escolar & $\begin{array}{l}\text { Enfermeira Zulema de } \\
\text { Castro Amado }\end{array}$ & $\begin{array}{l}\text { Retrata as atribuições de enfermeiras em saúde } \\
\text { pública com enfoque na área escolar. }\end{array}$ \\
\hline 1933 & $\begin{array}{l}\text { Cooperação da enfermeira de } \\
\text { saúde pública junto ao serviço de } \\
\text { hygiene infantil }\end{array}$ & Enfermeira Anália Banha & $\begin{array}{l}\text { Focaliza a atuação da enfermeira em saúde } \\
\text { publica em um caso de desnutrição infantil. }\end{array}$ \\
\hline 1934 & Serviço de Dietética Infantil & $\begin{array}{l}\text { Aluna Margarida dos Passos } \\
\text { Roza }\end{array}$ & $\begin{array}{l}\text { Analisa os distúrbios nutritivos e as doenças } \\
\text { ocasionadas por eles na primeira infância. }\end{array}$ \\
\hline 1934 & Cuidado Geral & $\begin{array}{l}\text { Enfermeira Juracy Serpa } \\
\text { Pyrrho }\end{array}$ & $\begin{array}{l}\text { Apresenta um caso clinico de uma criança com } \\
\text { tuberculose e a atuação da enfermeira }\end{array}$ \\
\hline 1934 & $\begin{array}{l}\text { Cuidados indispensáveis dos seios } \\
\text { no período da gestação e durante } \\
\text { a lactação }\end{array}$ & Aluna Maria Oliveira Regis & $\begin{array}{l}\text { Descreve os cuidados com os seis no período da } \\
\text { gestação e da amamentação. }\end{array}$ \\
\hline 1934 & Higiene Infantil & Enfermeira Edith de Souza & $\begin{array}{l}\text { Discorre sobre higiene pré-natal e higiene } \\
\text { infantil. }\end{array}$ \\
\hline 1935 & $\begin{array}{l}\text { Da mortalidade infantil e suas } \\
\text { causas }\end{array}$ & Enfermeira Mafalda Leone & $\begin{array}{l}\text { Aborda as causas da mortalidade infantil, assim } \\
\text { como as medidas preventivas }\end{array}$ \\
\hline 1937 & Banho de recém-nascido & $\begin{array}{l}\text { Aluna Maria de Oliveira } \\
\text { Regis }\end{array}$ & Descreve a técnica do banho em recém-nascido. \\
\hline 1937 & $\begin{array}{l}\text { Aspecto social das doenças nas } \\
\text { crianças }\end{array}$ & $\begin{array}{l}\text { Enfermeira Célia Peixoto } \\
\text { Alves }\end{array}$ & $\begin{array}{l}\text { Abrange os cuidados durante a gestação e após o } \\
\text { parto }\end{array}$ \\
\hline 1937 & $\begin{array}{l}\text { Aspecto social das doenças nas } \\
\text { crianças }\end{array}$ & $\begin{array}{l}\text { Enfermeira Célia Peixoto } \\
\text { Alves }\end{array}$ & $\begin{array}{l}\text { Aborda aspectos relativos ao desenvolvimento } \\
\text { infantil. }\end{array}$ \\
\hline 1937 & Apanhados de técnica & Enfermeira Zaira C. Vidal & $\begin{array}{l}\text { Descreve a técnica de realização de um } \\
\text { cataplasma. }\end{array}$ \\
\hline 1938 & $\begin{array}{l}\text { Técnica para colheita de urina em } \\
\text { criança }\end{array}$ & Enfermeira Glória Dias & $\begin{array}{l}\text { Descreve a técnica de coleta de urina em } \\
\text { crianças. }\end{array}$ \\
\hline 1938 & $\begin{array}{l}\text { Aspecto social das doenças nas } \\
\text { crianças }\end{array}$ & $\begin{array}{l}\text { Enfermeira Célia Peixoto } \\
\text { Alves }\end{array}$ & $\begin{array}{l}\text { Aborda aspectos sobre pré-natal, gravidez e visita } \\
\text { domiciliar de enfermeiras. }\end{array}$ \\
\hline 1938 & $\begin{array}{l}\text { Pontos essenciais para um serviço } \\
\text { de enfermagem hospitalar } \\
\text { adequado }\end{array}$ & Enfermeira Bertha Pullen & $\begin{array}{l}\text { A autora engloba Questões relativas à } \\
\text { administração hospitalar. }\end{array}$ \\
\hline 1941 & Apanhados de técnica & Enfermeira Zaira C. Vidal & $\begin{array}{l}\text { Descreve as técnicas de aplicações Quentes e frias } \\
\text { e suas indicações. }\end{array}$ \\
\hline
\end{tabular}

Fonte: Annaes de Enfermagem, período 1932-1941.

\section{Quadro 1. Publicações de enfermeiras e alunas da Escola de Enfermagem Anna Nery nos Annaes de Enfermagem (1932-1941).}

\section{REFERÊNCIAS}

1. Carvalho AC. Edith de Magalhães Frankel. São Paulo: Universidade de São Paulo; 1992.

2. Santos TCF, Barreira IE. O poder simbólico da enfermagem Norte-Americana no ensino da Enfermagem na capital do Brasil (1928-1938). Rio de Janeiro: Editora Anna Nery; 2002.

3. Lobo RH. Era nova [editorial]. Annaes Enferm 1932; I(I): 5-6.

4. Santos TCF e Gomes MLB. Nexos entre pós-graduação e pesquisa em Enfermagem no Brasil. Rev Bras Enferm 2007;
60(1): $92-5$

5. Bourdieu P. Os usos sociais da ciência. Por uma sociologia clínica do campo científico. São Paulo: Editora da UNESP; 2004.

6. Ariés P. História social da criança e da família. $10^{\mathrm{a}}$ ed. Rio de Janeiro: LTC; 2005.

7. Codo W. Educação: carinho e trabalho. 10ª ed. Petrópolis: Vozes; 1999. 